\title{
CORRELATION OF SHEAR WAVE VELOCITY WITH SPT-N FOR A TOWER- BUILDING SITE AT ERBIL CITY
}

\author{
AHMED MOHAMMED HASAN ${ }^{1, *}$, YOUSIF ISMAEL MAWLOOD ${ }^{*}$, AZAD A. AHMED ${ }^{* *}$ \\ and HAWKAR HASHIM IBRAHIM* \\ *College of Engineering, University of Salahaddin -Erbil, Kurdistan Region- raq \\ ${ }^{* *}$ Andrea Engineering Tests Laboratory, Erbil, Kurdistan Region-Iraq
}

(Accepted for Publication: December 8, 2020)

\begin{abstract}
Measurement of shear wave velocity (Vs) plays a crucial role in ground movements around geotechnical structures such as building foundations in the urban area and tunnels. Basically, measuring Vs often requires when seismic properties of soils are essential to be calculated, such as elastic shear modulus. Multichannel analysis of surface wave (MASW) is one of the seismic methods which employs surface waves to measure Vs. It is often not available along with site investigation due to high cost, complicated technical analysis, noise pollution, space constraints, etc. Hence, it is essential to predict Vs through correlating it to other soil parameters such as standard penetration test blows count (SPT-N). Therefore, the main focus in the current study was to correlate between Vs and SPT-N using an empirical equation likely applied for clay soils. A complementary subsoil investigation was performed of a towerbuilding at Erbil City, including SPT-N values for three boreholes and their corresponding MASW measurements. These data were, in turn, used to estimate Vs from corrected SPT-N. The currently proposed equation compared with the existing ones in the literature. The comparison shows that the proposed equation predicts the values of Vs as good as those available in the literature for both of the datasets in the current and the previous studies.
\end{abstract}

KEYWORDS: Shear Wave Velocity; Standard Penetration Test; Site Investigation; Seismic Properties; Empirical Equation

\section{INTRODUCTION}

I $n$ the last three decades, the application of the shear wave velocity Vs is significantly increased to cover, e.g., creep, aging, soil anisotropy, cavity detection, assessing the liquefaction potential, sinkholes, building foundations in the urban area, tunnels, mapping stratigraphic layers, seismic response of soils (Atkinson, 1991; Dai et al., 2013; Hasan \& Wheeler, 2014; Jovičić \& Coop, 1998; Ng \& Yung, 2008; Pennington et al., 2001; Seed et al., 1983). Dynamic response of soils is highly dependent on the small strain shear modulus $G$ and shear wave velocity $V_{s}$. There is a strong correlation between these two parameters by Equation (1):

$$
G=\rho V_{s}^{2}
$$

where $\rho$ is the bulk density of the soil. The value of $V_{s}$ is significantly changed by changing soil density, void ratio, stress state, stress history, ageing, cementation, etc. (Callisto \& Rampello, 2002; Dai et al., 2013; Hardin \& Blandford, 1989; Houlsby \& Wroth, 1991). $G_{\max }$ or $G_{o}$ is strain level-dependent; its value greatly reduces with increasing strain level (see, Atkinson, 1991). $G_{\max }$ is calculated from Vs where the strain levels are less than $3 \%$ to $10 \%$ (Atkinson, 1991). Vs can be measured in the geotechnical laboratory by resonant column device (Allen \& Stokoe, 1982; Hall \& Richart, 1963) or bender element (Brignoli et al., 1996; Dyvik \& Olsen, 1989; Hasan \& Wheeler, 2016; Lee \& Santamarina, 2005; Shirley \& Hampton, 1978). Laboratory testing of $V_{s}$ requires advanced testing equipment and undisturbed samples. However, small undisturbed samples will not represent the whole soil profile in the field. Therefore, in situ measurement of Vs is highly recommended. Even though such measurement is rarely performed in the most filed exploration

ahmed.hasan@su.edu.krd, yousif.mawlood@su.edu.krd, azad@andrealab.com, hawkar.ibrahim@su.edu.krd 
due to, for example, extra cost in site investigation, space constraints, etc.

Geophysical methods such as Multichannel Analysis of Surface Wave (MASW) is one of the non-destructive testing (not requires borehole) popular felid seismic method, which uses surface waves to measure Vs (Park et al., 1999). It is unlike other invasive field methods such as down-hole logging and cross-hole logging that requires boreholes (Andrus et al., 2004).

There are many statistical correlations between Vs and important variables such as SPT-N (Jafari et al., 2002), undrained shear strength (Dickenson, 1995) and cone penetration test resistance (Sykora, 1983) to predict the value of Vs, because, during most field exploration, the geophysical data do not often exist in the same area. Therefore, numerous researchers have proposed statistical correlations in the form of power function between SPT-N and Vs. Proposing such relations avoids geotechnical designers to perform additional geophysical tests in the same area where only geotechnical reports are available (Akin et al., 2011). A detailed review of the statistical correlation between Vs and SPT-N is presented by Dikmen (2009); Jafari et al. (2002) for a wide range of soil types including sandy soils (Sykora, 1983), silty soils (Lee and Santamarina, 2005), clay soils (Imai, 1977) and all soils (Ohta \& Goto, 1978). In the literature, almost all the correlations have been proposed in the form of $\mathrm{Vs}=\mathrm{AN}^{\mathrm{B}}$ where $\mathrm{A}$ and $\mathrm{B}$ are constants.

In the current study, based on the measured data of $\mathrm{V}_{\mathrm{s}}$ and SPT-N in the same area, a correlation between them is proposed in a specific form of the regression model for clay soils, which is different from those available in the literature. Then, the current proposed model is compared with the existing proposed models in the literature presented in Table 1. Further evaluation is performed on the current model by predicting the value of $\mathrm{V}_{\mathrm{s}}$ from the existing dataset for clay soils in the literature using the current proposed model.

Table (1): Existing correlations between Vs and SPT-N only for clay soils

\begin{tabular}{cll}
\hline $\begin{array}{c}\text { Equation } \\
\text { No. }\end{array}$ & Author(s) & Equation form literature \\
\hline 1 & Imai (1977) & $V_{s}=80.2 N^{0.292}$ \\
\hline 2 & Lee (1990) & $V_{s}=114.43 N^{0.31}$ \\
\hline 3 & Athanasopoulos (1970) & $V_{s}=76.55 N^{0.445}$ \\
\hline 4 & Jafari et al. (2002) & $V_{s}=27 N^{0.73}$ \\
\hline 5 & Hasancebi and Ulusay (2007) & $V_{s}=97.89 N^{0.269}$ \\
\hline 6 & Dikmen (2009) & $V_{s}=44 N^{0.48}$ \\
\hline 7 & Lee (1992) for Silt and Clay & $V_{s}=122.7(N+1.2)^{0.26}$ \\
\hline 8 & Lee (1992) for Clay & $V s=131.7(N+1.2)^{0.24}$ \\
\hline 9 & Pitilakis et al. (1999) & $V_{s}=128.1 N^{0.27}$ \\
\hline 10 & Ulugergerli and Uyanik (2007) & $V_{s}=107.63 N^{0.237}$ \\
\hline 11 & Ohta \&Goto (1978) $Q^{*}$ & $V_{s}=82.4 N^{0.34}$ \\
\hline
\end{tabular}

*Geological age; Q= Quaternary, the middle part of Erbil Plain is mostly covered by Quaternary sediments (Hassan et al., 2010).

ahmed.hasan@su.edu.krd, yousif.mawlood@su.edu.krd, azad@andrealab.com, hawkar.ibrahim@su.edu.krd 


\subsection{Field Work}

\section{METHODOLOGY}

\subsubsection{Method of Drilling}

The boring equipment used in carrying out the fieldwork was two multi-method drilling rigs using the rotary drilling method by wash the boring process. The thin wall tube samplers (Shelby Tube) used according to (ASTM D1587, 2000) for obtaining undisturbed samples. The depths of boring of $(30-35) \mathrm{m}$ were selected to extend to underneath the zone of influence of significant foundation pressure to relatively incompressible materials. The method of drilling was carried out following the standards of the American Society for Testing and Materials (ASTM D5783, 2018).

\section{i. Disturbed Samples}

The disturbed samples were obtained, according to ASTM D1586 (2018), at intervals of (2-3) meters, and as required to determine the classification of the soil layers. The samples that were secured by the Standard Split Spoon Sampler were also used as disturbed samples. All disturbed samples were sent to the laboratory for further examination and testing; such as visual classification (ASTM D2488, 2017), specific gravity (ASTM D854, 2014), grain size distribution (ASTM D6913, 2017), and liquid and plastic limits (ASTM D4318, 2017). Table 2 shows index and geotechnical properties of soils in borehole No. 1 .

\section{ii. Undisturbed Samples}

Undisturbed samples were obtained at (1-3) meter intervals or change of strata only. After extraction, the samples were trimmed off, capped with paraffin wax, and sealed properly at both ends. The samples were then dispatched to the laboratory for further examination and testing, such as natural moisture content and unit weight (ASTM D2216, 2019).

Table (2): Index and geotechnical properties of soils in B.H. No. 1

\begin{tabular}{|c|c|c|c|c|c|c|c|c|c|c|}
\hline \multicolumn{4}{|c|}{ Location of Specimen } & \multicolumn{3}{|c|}{ Index Properties } & \multirow{2}{*}{$\begin{array}{l}\text { Natural } \\
\text { Water } \\
\text { Content } \\
\%\end{array}$} & \multirow{2}{*}{$\begin{array}{c}\text { Dry } \\
\text { Density } \\
\mathrm{KN} / \mathrm{m}^{3}\end{array}$} & \multirow[b]{2}{*}{$\begin{array}{l}\text { Specific } \\
\text { Gravity }\end{array}$} & \multirow{2}{*}{$\begin{array}{c}\text { Sieve Analysis } \\
\% \\
\text { Passing No. } 200\end{array}$} \\
\hline $\begin{array}{l}\text { B.H. } \\
\text { No. }\end{array}$ & $\begin{array}{l}\text { Sample } \\
\text { No. }\end{array}$ & Depth (m) & $\begin{array}{l}\text { Sample } \\
\text { Type }\end{array}$ & $\begin{array}{l}\mathrm{LL} \\
\%\end{array}$ & $\begin{array}{l}\text { PL } \\
\%\end{array}$ & $\begin{array}{l}\mathrm{PI} \\
\%\end{array}$ & & & & \\
\hline \multirow[t]{14}{*}{1} & 1 & $0.0-0.5$ & DS & & & & & & & \\
\hline & 2 & $1.0-1.5$ & US & & & & 11.6 & 16.3 & & \\
\hline & 3 & $2.0-2.5$ & DS & 41 & 27 & 14 & & & & 54.2 \\
\hline & 4 & $3.0-3.5$ & US & & & & 11.8 & 15.2 & 2.68 & \\
\hline & 5 & $4.0-4.5$ & DS & 45 & 24 & 21 & & & & \\
\hline & 6 & $5.5-6.0$ & DS & & & & & & & 61.7 \\
\hline & 7 & $7.0-7.5$ & DS & 48 & 23 & 25 & & & & 89.8 \\
\hline & 8 & $8.5-9.0$ & US & 49 & 28 & 21 & 21.8 & 15.9 & 2.70 & \\
\hline & 9 & $9.5-10.0$ & DS & & & & & & & 98.4 \\
\hline & 10 & $11.0-11.5$ & DS & 40 & 22 & 18 & & & & \\
\hline & 11 & $13.0-13.5$ & US & & & & 18.6 & 16.4 & 2.69 & 93.1 \\
\hline & 12 & $15.0-15.5$ & DS & 47 & 24 & 23 & & & & \\
\hline & 13 & $17.0-17.5$ & DS & 38 & 22 & 16 & 17.3 & & & 91.2 \\
\hline & 14 & $19.5-20.0$ & DS & 34 & 21 & 13 & & & & 64.7 \\
\hline
\end{tabular}

ahmed.hasan@su.edu.krd, yousif.mawlood@su.edu.krd, azad@andrealab.com, hawkar.ibrahim@su.edu.krd 


\section{iii. In-Situ Testing}

\section{Standard Penetration Test (SPT)}

In the course of drilling work, the consistency of the soil was measured at several depths by Standard Penetration Test (SPT). The test was performed following (ASTM D1586, 1999). The test involves recording the number of blows of 140 lbs. (63.5 kg) Standard Hammer with a 30inch $(76 \mathrm{~cm})$ drop to drive the 2-inch $(50.8 \mathrm{~mm})$ diameter Standard Split Spoon Sampler into the soil a distance of 12 inches $(30.5 \mathrm{~cm})$. At the hard layers, the cone of (60) degree used instead of split spoon sampler to serve the same purpose as mentioned above.

The corrected $\mathrm{N}$-values with depth are given in Figure 1.

\subsubsection{MASW}

In this study, a specific correlation between $\mathrm{V}_{\mathrm{s}}$ and SPT-N is proposed, based on the two geotechnical reports (including field and laboratory tests) for more than three boreholes on the site of the foundation of the towerbuilding project in Erbil City, Kurdistan ( $36^{\circ} 10^{\prime} 47.28^{\prime \prime} N \quad 44^{\circ} 01^{\prime} 29.79^{\prime \prime} E$ elev $1371 \mathrm{ft}$
). From Engineering Consulting Bureau (ECB) College of Engineering-Salahaddin UniversityErbil and Andrea Engineering Testing Laboratory (AETL)-Baghdad, the MASW Survey for the foundation of a tower-building project was recommended in order to explore more the properties and behaviour of the soil layers deeper than $27 \mathrm{~m}$ from the foundation level. This recommendation suggested to that depth by ECB and AETL, because the results of field were slightly ambiguous due to collapsing behaviour of the soil in such depths. In addition, it was expected that cavities could be detected there based on previous investigations in the Erbil city.

Three MASW transverses were performed on the surface of the foundation of the towerbuilding by Amak Geophysical Exploration and Scientific Appliances Company on July 2019, to investigate the subsurface soil layers to a depth more than $40 \mathrm{~m}$. Figure 2 shows the locations of the three MASW transverse along with the corresponding boreholes on the site. However, the Google map of the three MASW traverses shown in Figure

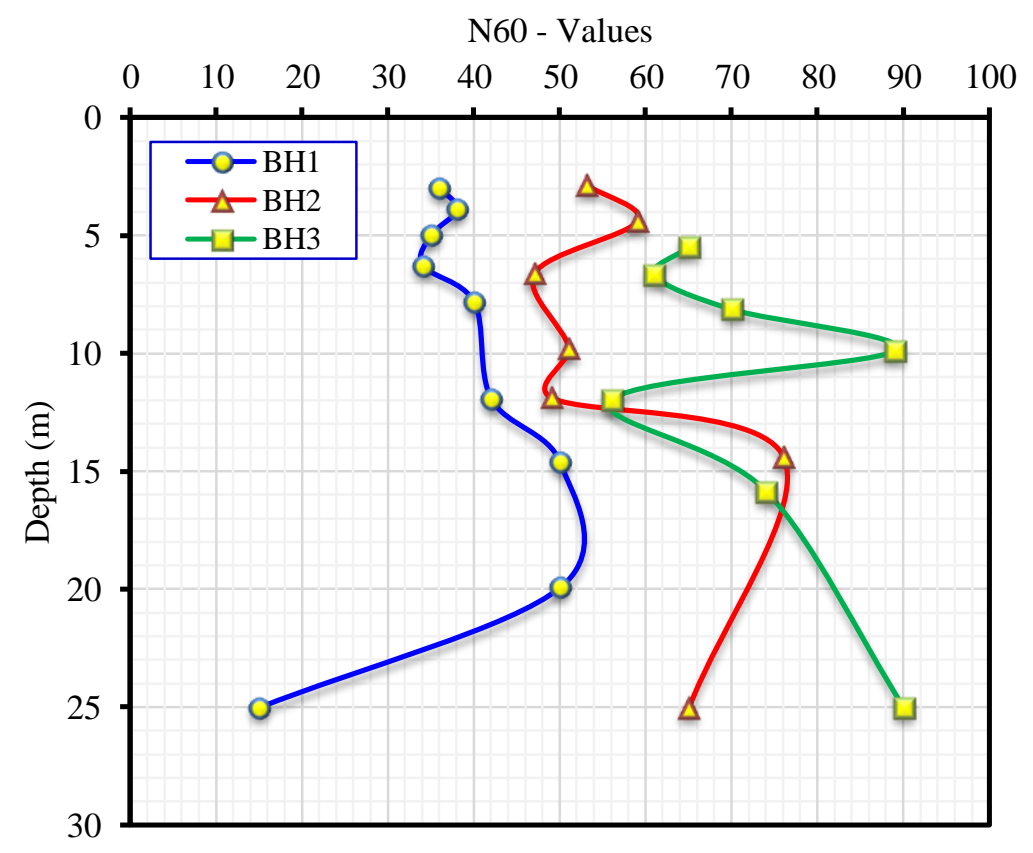

Fig. (1): N60 values versus depth of the three boreholes

ahmed.hasan@su.edu.krd, yousif.mawlood@su.edu.krd, azad@andrealab.com, hawkar.ibrahim@su.edu.krd

\footnotetext{
${ }^{1}$ Corresponding author: College of Engineering, Salahaddin University-Erbil, Kurdistan Region, Iraq
} 


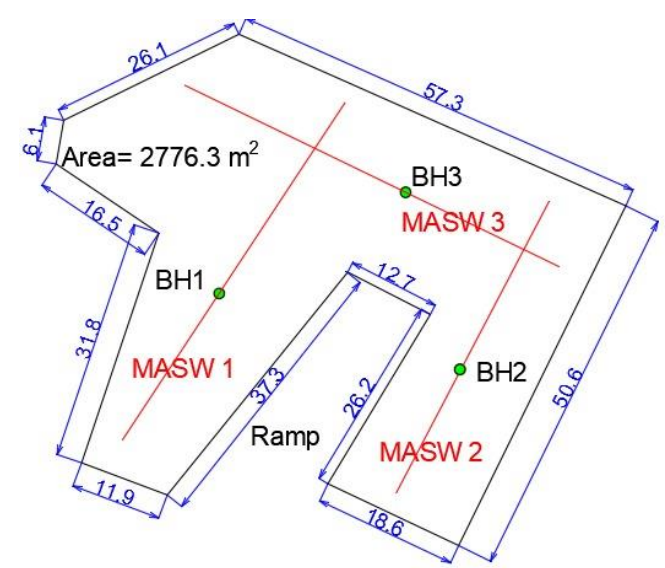

Fig. (2): The tower-building site plan with the locations of 3 boreholes and MASW-1, MASW2, MASW-3 traverses

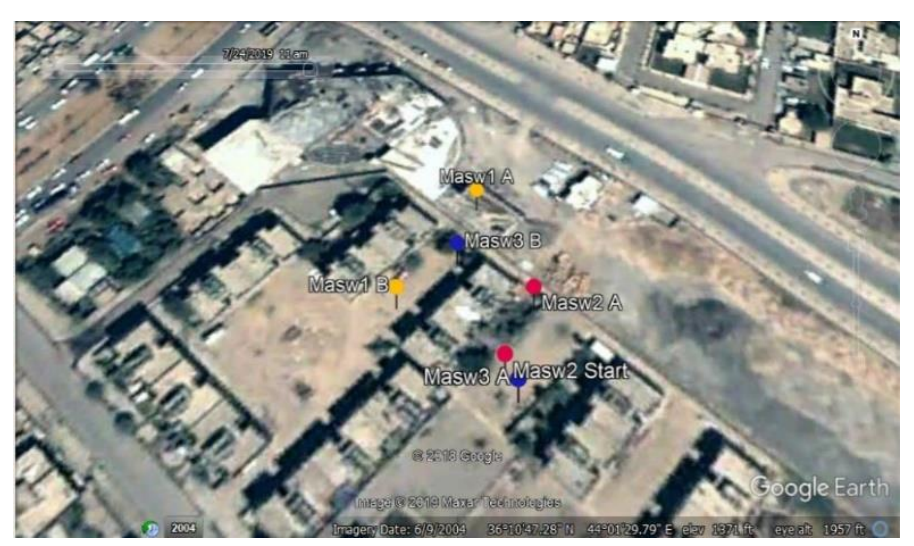

Fig. (3): shows the locations of MASW-1 (dark yellow), MASW -2 (Red), and MASW -3 (blue) at tower-building, Erbil.
In the current study, the following equipment was used to perform the three MASW transverse: 1) Terraloc Pro Seismograph (which is presented in Figure 4), 2) low-frequency geophones (which is also presented in Figure 4), 3) GeoGiga software (Seismic Pro 8,3- Surface Plus), 4) two cables set of 144.0 meters, a heavy machine that used as seismic source vibrator (Figure 7) and 5) Portable drilling machine.

The standard procedure of the MASW could be shortly described as follow. First, field experimental data acquisition from a multichannel seismograph is carried out. Secondly, the experimental dispersion curve (Figure 5) and initial shear wave velocity (Figure 6) are plotted from signal processing of the acquiring filed records. Thirdly, the estimated shear wave velocity profile can be plotted from the inversion process of the dispersion curves.

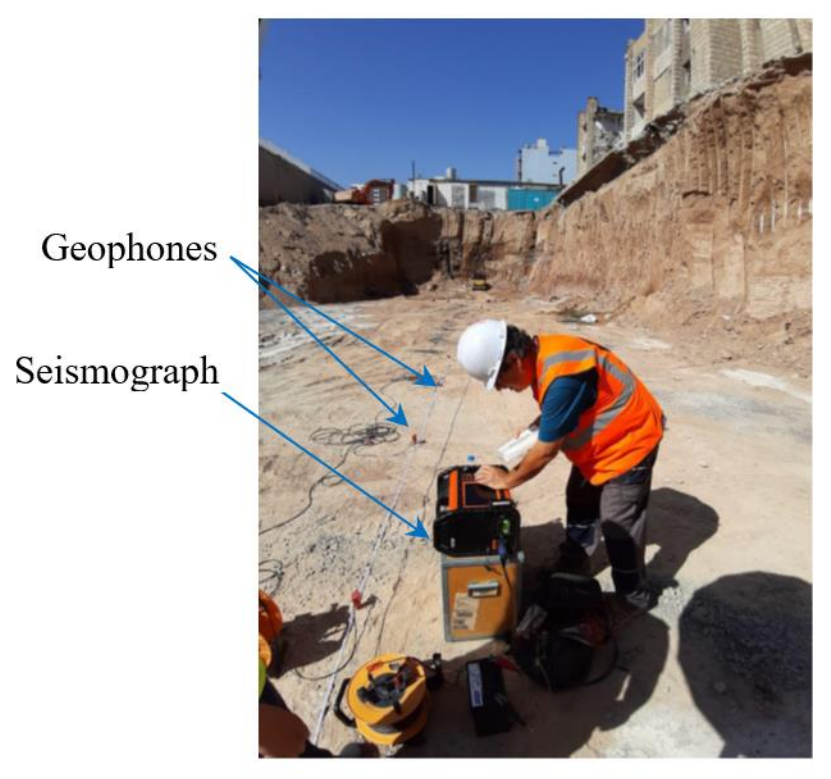

Fig. (4): The seismograph (Terraloc Pro) at the tower-building site, Erbil.

ahmed.hasan@su.edu.krd, yousif.mawlood@su.edu.krd, azad@andrealab.com, hawkar.ibrahim@su.edu.krd 


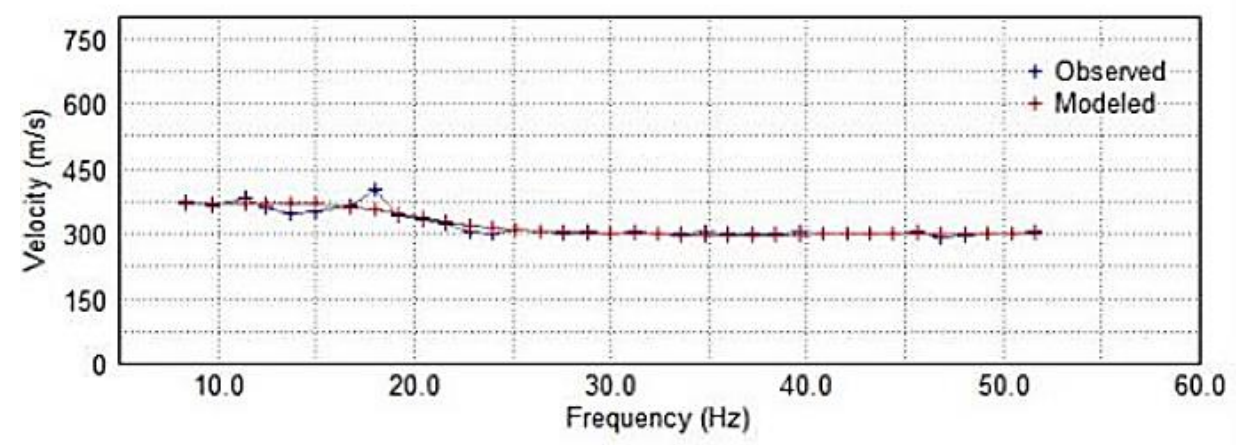

Fig. (5): Dispersion curves

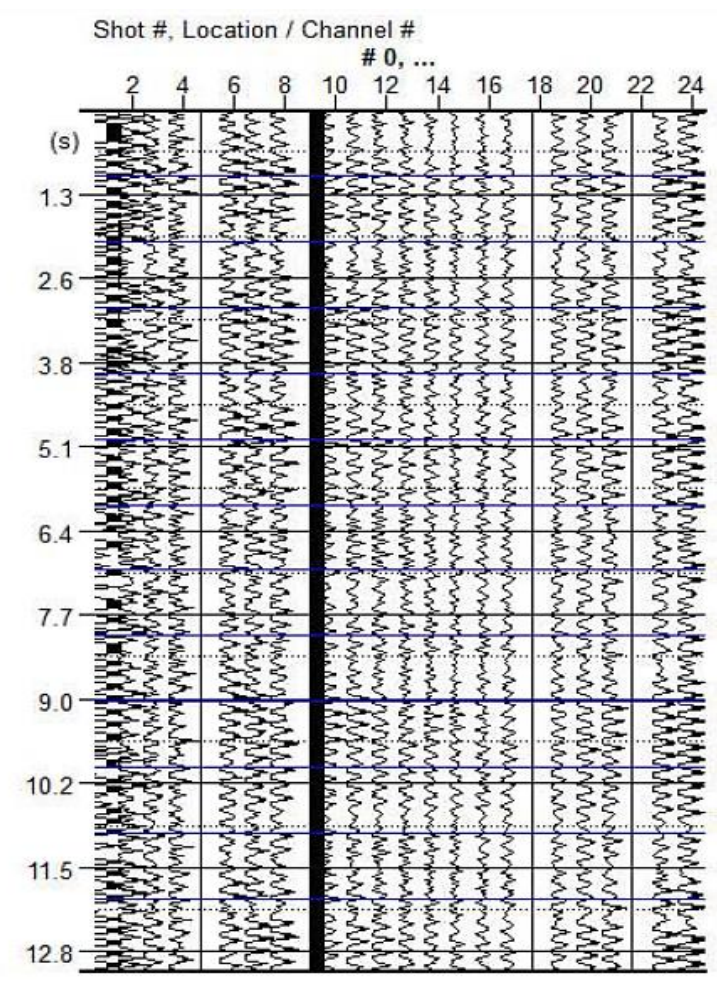

Fig. (6): MASW data processing software for initial shear velocities model

The MASW survey was carried out, in the present work, at the tower-building site using 26 channels seismograph, and low-frequency geophones $(4.5 \mathrm{~Hz})$. The MASW spread length is 24.0-48.0 meters using 24 geophones of low frequency. The inter-distance between two geophones is $1.0-2.0$ meters for high resolution and depth. Active and passive recordings methods were followed in this survey (Park et al., 2005). For each MASW spread there are three recordings. The seismograph settings were arranged for $4.0 \mathrm{sec}, 8.0$, and $13.0 \mathrm{sec}$ as recording intervals and $0.1-0.4$ msec sampling intervals. The hammer impact and vibrator machine (Figure 7) were used as sources for energy at different shot points distances. MASW-1 and MASW-3 traverses were 48.0 meters in lengths, while MASW-2 was 24.0 meters in length. At the MASW-2 location, there was limited space due to the existence of an under-construction building. The three traverses were at a level -7.0 meter from the natural ground (i.e. earthworks or excavations were done at this site). Therefore, the MASW results are all relative to the level - 7.0.

ahmed.hasan@su.edu.krd, yousif.mawlood@su.edu.krd, azad@andrealab.com, hawkar.ibrahim@su.edu.krd

${ }^{1}$ Corresponding author: College of Engineering, Salahaddin University-Erbil, Kurdistan Region, Iraq 


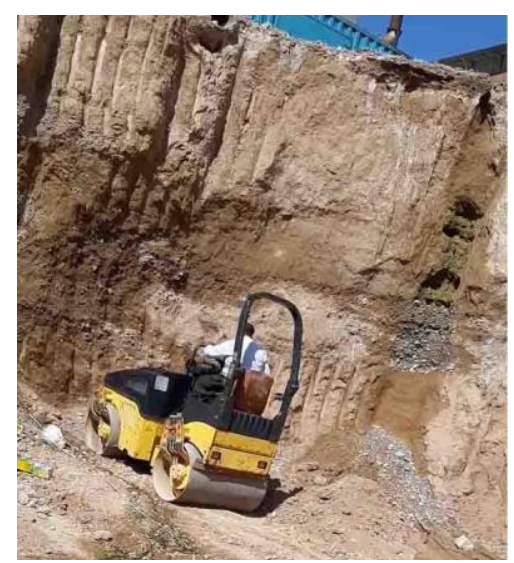

Fig. (7) :The heavy machine that used as seismic source vibrator at tower-building site

\section{RESULTS AND DISCUSSION \\ 3.1 Subsurface Profile}

The soil investigation works have passed through several processes to decide on the depth of the deep foundation that supposed to resist the load of a Residential Tower. The first round of the soil exploration was carried out by means of drilling single borehole to a pre-designed depth of $50 \mathrm{~m}$. However, the drilling of the borehole has been terminated at a depth of around $30 \mathrm{~m}$ below the existing excavated ground level at around $(-6 \mathrm{~m}$ to $-7 \mathrm{~m})$. The reason for the termination was the skipping of the drilling water through the strata, and the lack of the drilling water circulation indication of voids at the indicated depth and no further soils could be a lift to the surface. The mentioned tests were conducted in July 2019 by the Engineering Consultancy Bureau, College of Engineering, University of Salahaddin, Erbil. Consequently, it was recommended in the report that was prepared by the Engineering Consultancy Bureau of University of Salahaddin to seek the aid of geophysical study to explore the subsoil to extended depth further. The test was conducted on the same month of July 2019, and the conclusion of the tests indicated that there is a high porous material available from the depth of $25 \mathrm{~m}$ to $48 \mathrm{~m}$ below the excavated layer. This conclusion has proven that the outcome of the borehole's drilling where the wash water started to seep suddenly within the layer.

The subsoil strata encountered at the investigated locations show stratification of soil at the position of samples along with the depth for the investigated area. The subsoil strata at the site explored by three boreholes from $30 \mathrm{~m}$ to 35 m depth.
From the values of specific gravity, consistency indices and according to the Unified Soil Classification System (USCS), the majority of the Silty Clay layer is classified as CL, i.e., Silty Clay with low to medium plasticity while the thin Gravelly layers are categorized as GC.

The water table was not encountered, during the time of the investigation.

\subsection{The Proposed Empirical Equation}

Field tests involved SPT-N on the towerbuilding site in Erbil was used to investigate potential expressions for shear wave velocity (Vs). As stated above, the Minitab 18 software (Minitab is a statistics package similar to Statistical Package for the Social Sciences, SPSS) was used to optimise the correlation between Vs and SPT-N, by examining a wide range of linear and non-linear regression equation forms. At the end of the optimisation, the following specific mathematical form for the relationship linking $\mathrm{Vs}$ and corrected $\mathrm{N}$-values:

$$
V_{s}^{A}=B N-C N^{2}+D N^{3}
$$

where $\mathrm{A}, \mathrm{B}, \mathrm{C}$, and $\mathrm{D}$ are constants.

The regression analysis of the Minitab 18 changes the coefficients of Equation (2) (A, B, $C$, and D) to determine a set of values that minimises the sum of the squares of the errors between predicted and measured values of the dependent variable (Vs). The regression analysis proposed the following best-fit values for the constants in Equation (2): $\mathrm{A}=0.27, \mathrm{~B}=$ $0.22048, \mathrm{C}=-0.00338, \mathrm{D}=0.00001$. The corresponding value for the coefficient of determination $\mathrm{R}^{2}$, adjusted $\mathrm{R}^{2}$, and $\mathrm{P}$-Value were $99.70 \%, 99.64 \%$, and $<0.05$, respectively. Therefore, the final form of Equation (2) is:

ahmed.hasan@su.edu.krd, yousif.mawlood@su.edu.krd, azad@andrealab.com, hawkar.ibrahim@su.edu.krd 


$$
V_{s}^{0.27}=0.220481 N-0.00338 N^{2}+0.00001 N^{3}
$$

The ability and the validity of the form in Equation (3) are rigorously examined by comparing it with the other equations or other datasets from in the previous works in the literature in the next sub-sections.

\subsection{Comparison with other Equations from the Literature}

In order to test the ability of the proposed expression in the current study to those have been proposed expressions in the literature, the experimental field test results from SPT-N were used to predict the values of Vs. Figure 8 shows the comparison between $\mathrm{R}^{2}$ for the measured and predicted Vs using the currently proposed equation and the 11 previous equations, which presented in Table 1, for the dataset obtained in this study. It can be observed from Figure 8 that the value of the $\mathrm{R}^{2}$ for Equation (1) is the highest $(0.4749)$. The second best value of the $R^{2}$ $(0.4691)$ is generated by an equation proposed by Lee (1992); whereas, the rest of the equations seem that they predict very close values of the $\mathrm{R}^{2}$ ranged between 0.3850 to 0.3862 . This comparison suggests that the proposed expression in this study is performed as well as the other equations in Table 1 for clay soils at least for the field exploration dataset in this study. This confirms that it is possible to propose an equation to has a form differ than the common form of $\mathrm{V}_{\mathrm{s}}=\mathrm{AN}^{\mathrm{B}}$. To prove further that the form of Equation (1) works well, the Equation (1) tested by using the dataset from the literature (see the next subsection).

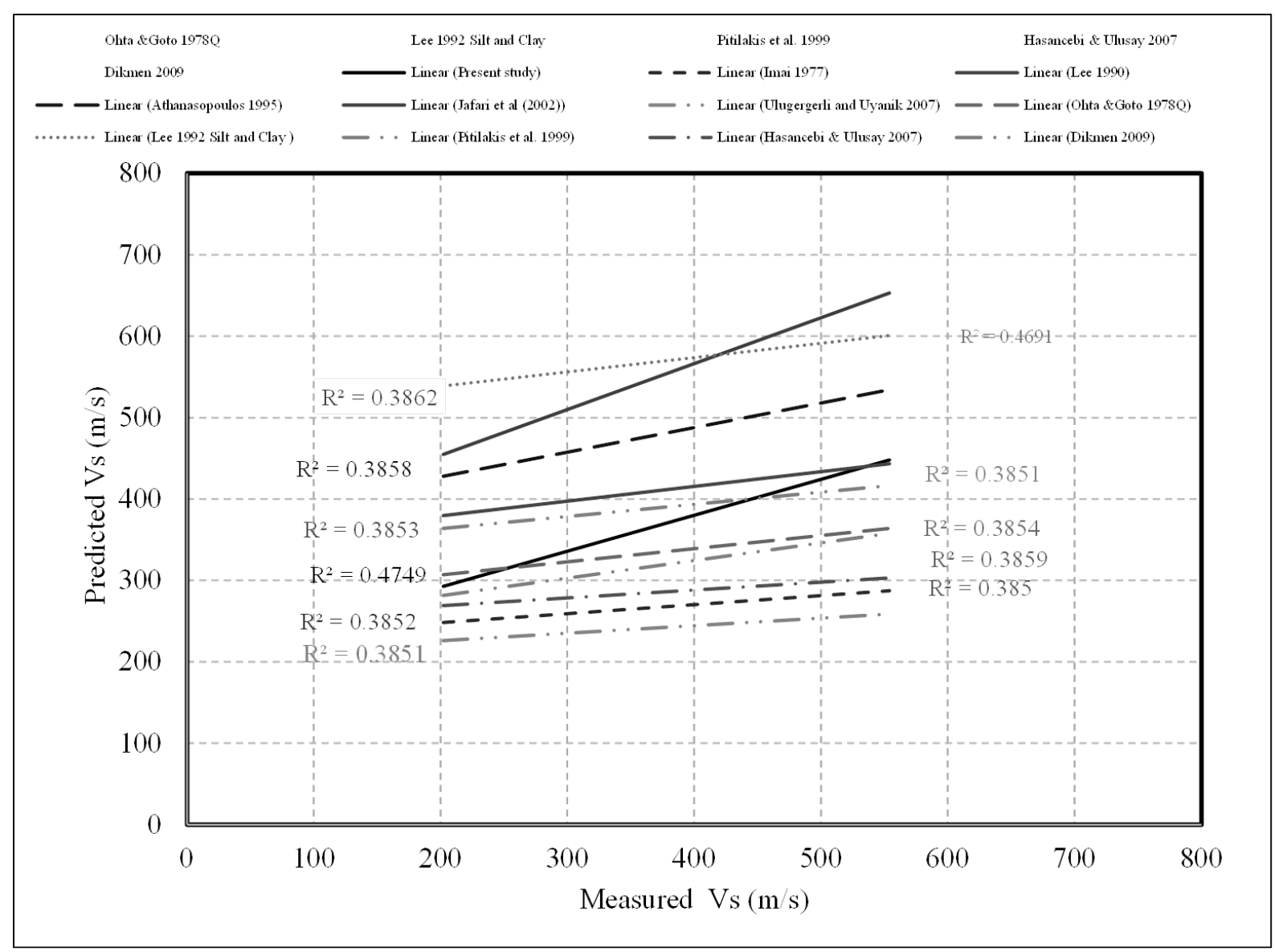

Fig. (8): $\mathrm{R}^{2}$ between measured and predicted $V \mathrm{~s}$ for the current proposed and 11 previous equations

ahmed.hasan@su.edu.krd, yousif.mawlood@su.edu.krd, azad@andrealab.com, hawkar.ibrahim@su.edu.krd 


\subsection{Comparison Against other SPT-N Datasets from Previous Studies}

Figure 9 shows the comparison of $\mathrm{R}^{2}$ between measured and predicted Vs using Equation (1) for current dataset and two datasets from the literature to present the quality of the performance of the currently proposed equation. Investigation of Figure 9 reveals that the Equation (1) can almost equally predict very well the values of the Vs from the dataset in the present study and the dataset in the work of the Hasancebi and Ulusay (2007). Investigation of
Figure 9 also shows that the prediction of Equation (3) is slightly less good, where the dataset used from the work of Park et al. (1999). In comparison to the performance of the previous equations in the literature (see Figure 8), it is possible to mention that Equation (3) predicts the values of the Vs as good as the previous ones in the literature. Overall, the currently proposed equation can better predict the values of Vs than those in the literature, even though the form of the earlier is different from the latter.

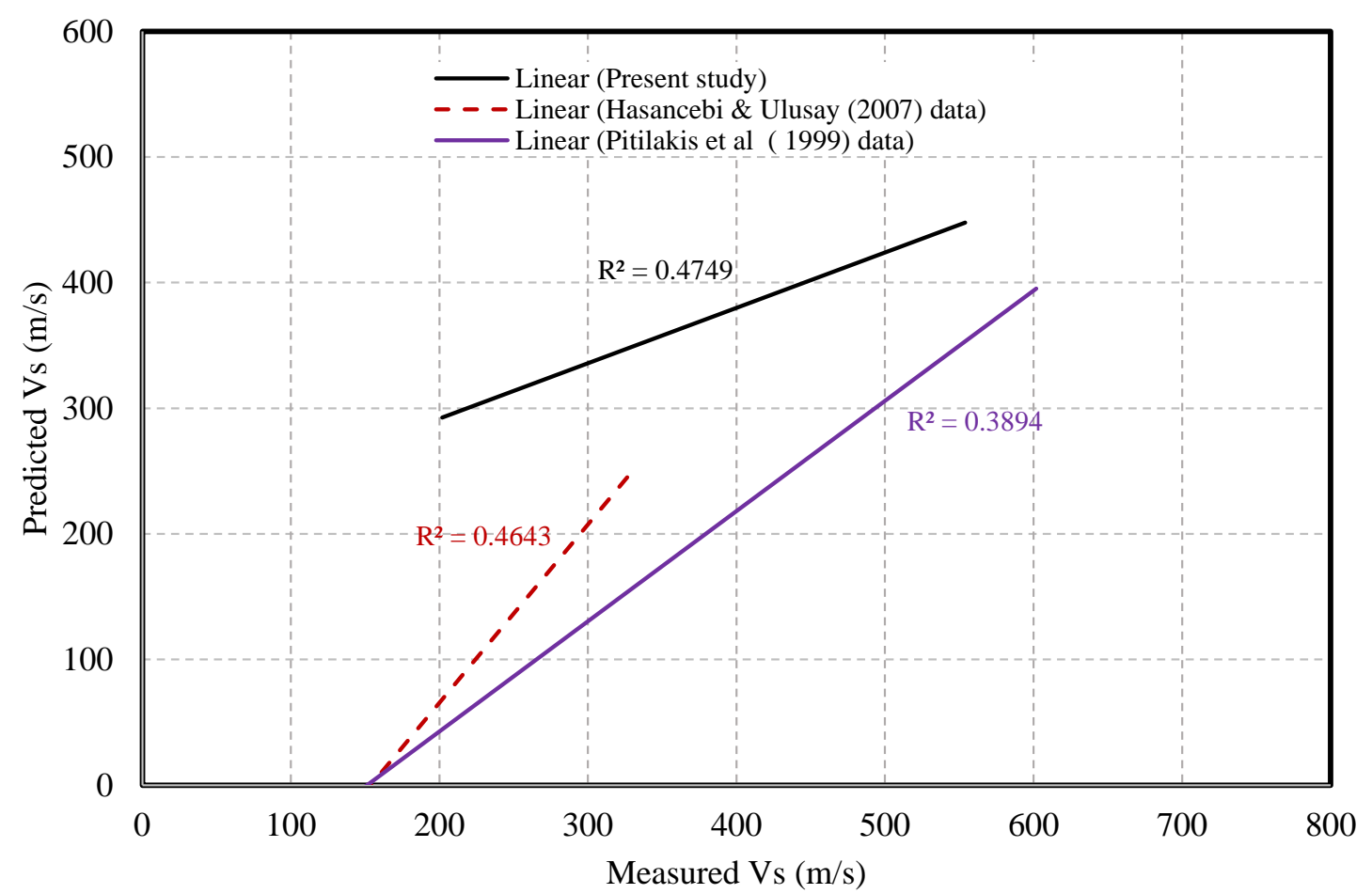

Fig. (9): $\mathrm{R}^{2}$ between measured and predicted $V \mathrm{~s}$ using Equation (1) for current dataset and 2 dataset from the literature

\section{CONCLUSIONS}

In the current study, several conclusions may be briefly presented as follow:

1. A different form of an equation between Vs and $\mathrm{N}$ has been proposed, which can predict well the values of Vs.

2. The proposed equation in the present study is able successfully to predict the values of Vs using limited data from the current study or datasets from the literate. ahmed.hasan@su.edu.krd, yousif.mawlood@su.edu.krd, azad@andrealab.com, hawkar.ibrahim@su.edu.krd 


\section{REFERENCES}

Akin, M. K., Kramer, S. L., \& Topal, T. (2011). Empirical correlations of shear wave velocity (Vs) and penetration resistance (SPT-N) for different soils in an earthquake-prone area (Erbaa-Turkey). Engineering Geology, 119(1), $1-17$.

doi:https://doi.org/10.1016/j.enggeo.2011.01.0 07

Allen, J., \& Stokoe, K. (1982). Development of resonant column apparatus with anisotropic loading: Geotechncal Engineering Center, Civil Engineering Department, University of ....

Andrus, R. D., Stokoe, K. H., \& Hsein Juang, C. (2004). Guide for shear-wave-based liquefaction potential evaluation. Earthquake Spectra, 20(2), 285-308.

ASTM D854. (2014). Standard Test Methods for Specific Gravity of Soil Solids by Water Pycnometer. In. West Conshohocken, PA: ASTM International.

ASTM D1586. (1999). Standard Test Method for Penetration Test and Split-Barrel Sampling of Soils. In. West Conshohocken, PA: ASTM International.

ASTM D1586. (2018). Standard Test Method for Standard Penetration Test (SPT) and SplitBarrel Sampling of Soils, ASTM International. In. West Conshohocken, PA: ASTM International.

ASTM D1587. (2000). Standard Practice for ThinWalled Tube Sampling of Soils for Geotechnical Purposes. In. West Conshohocken, PA: ASTM International.

ASTM D2216. (2019). Standard Test Methods for Laboratory Determination of Water (Moisture) Content of Soil and Rock by Mass. In. West Conshohocken, PA: ASTM International.

ASTM D2488. (2017). Standard Practice for Description and Identification of Soils (VisualManual Procedures), ASTM International. In. West Conshohocken, PA: ASTM International.

ASTM D4318. (2017). Standard Test Methods for Liquid Limit, Plastic Limit, and Plasticity Index of Soils. In. West Conshohocken, PA: ASTM International.

ASTM D5783. (2018). Standard Guide for Use of Direct Rotary Drilling with Water-Based Drilling Fluid for Geoenvironmental Exploration and the Installation of Subsurface Water-Quality Monitoring Devices. In. West Conshohocken, PA: ASTM International.

ASTM D6913. (2017). Standard Test Methods for Particle-Size Distribution (Gradation) of Soils
Using Sieve Analysis. In. West Conshohocken, PA: ASTM International.

Athanasopoulos, G. (1970). Empirical correlations Vso-NSPT for soils of Greece: A comparative study of reliability. WIT Transactions on The Built Environment, 15.

Atkinson, J. H. (1991). Experimental determination of stress - strain -time characteristics in laboratory and - in -situ tests. General report. Proc. 10th Eur. Conf. Soil Mech. and Fnd Engng, 3, 915-956. Retrieved from https://ci.nii.ac.jp/naid/10004560238/en/

Brignoli, E. G., Gotti, M., \& Stokoe, K. H. (1996). Measurement of shear waves in laboratory specimens by means of piezoelectric transducers. Geotechnical Testing Journal, 19(4), 384-397.

Callisto, L., \& Rampello, S. (2002). Shear strength and small-strain stiffness of a natural clay under general stress conditions. Géotechnique, $52(8)$, 547-560. doi:10.1680/geot.2002.52.8.547

Dai, S., Wuttke, F., \& Santamarina, J. C. (2013). Coda Wave Analysis to Monitor Processes in Soils. Journal of Geotechnical and Geoenvironmental Engineering, 139(9), 15041511. doi:doi:10.1061/(ASCE)GT.19435606.0000872

Dickenson, S. E. (1995). Dynamic response of soft and deep cohesive soils during the Loma Prieta Earthquake of October 17, 1989.

Dikmen, Ü. (2009). Statistical correlations of shear wave velocity and penetration resistance for soils. Journal of Geophysics and Engineering, 6(1), 61-72.

Dyvik, R., \& Olsen, T. (1989). Gmax measured in oedometer and DSS tests using bender elements. Paper presented at the Congrès international de mécanique des sols et des travaux de fondations. 12.

Hall, J. R., \& Richart, F. E. (1963). Dissipation of elastic wave energy in granular soils. Retrieved from

Hardin, B. O., \& Blandford, G. E. (1989). Elasticity of Particulate Materials. Journal of Geotechnical Engineering, 115(6), 788-805. doi:doi:10.1061/(ASCE)07339410(1989)115:6(788)

Hasan, A., \& Wheeler, S. (2016). Interpreting measurements of small strain elastic shear modulus under unsaturated conditions. Paper presented at the E3S Web of Conferences.

Hasan, A., \& Wheeler, S. J. (2014). Influence of compaction procedure on elastic anisotropy. Paper presented at the Proc. 5th International

ahmed.hasan@su.edu.krd, yousif.mawlood@su.edu.krd, azad@andrealab.com, hawkar.ibrahim@su.edu.krd

${ }^{1}$ Corresponding author: College of Engineering, Salahaddin University-Erbil, Kurdistan Region, Iraq 
Conference on Unsaturated Soils, Sydney, Australia.

Hasancebi, N., \& Ulusay, R. (2007). Empirical correlations between shear wave velocity and penetration resistance for ground shaking assessments. Bulletin of Engineering Geology and the Environment, 66(2), 203-213.

Hassan, K. M., Surdashy, A. M., \& Bapeer, G. B. (2010). The Study of the Physical Properties of Quaternary Sediments in the Middle Part of Erbil Plain, Kurdistan Region, North Iraq. Iraqi Bulletin of Geology and Mining, 6(1), 31-46.

Houlsby, G., \& Wroth, C. (1991). The variation of shear modulus of a clay with pressure and overconsolidation ratio. Soils and Foundations, 31(3), 138-143.

Imai, T. (1977). $P$ - and $S$-wave velocities of the ground in Japan. Paper presented at the 9th Int. Conf. on Soil Mechanics and Foundation Engineering.

Jafari, M. K., Shafiei, A., \& Razmkhah, A. (2002). Dynamic properties of fine grained soils in south of Tehran.

Jovičić, V., \& Coop, M. (1998). The measurement of stiffness anisotropy in clays with bender element tests in the triaxial apparatus. Geotechnical Testing Journal, 21(1), 3-10.

Lee, J.-S., \& Santamarina, J. C. (2005). Bender Elements: Performance and Signal Interpretation. Journal of Geotechnical and Geoenvironmental Engineering, 131(9), 10631070 doi:doi:10.1061/(ASCE)10900241(2005)131:9(1063)

Lee, S. H.-H. (1992). Analysis of the Multicollinearity of Regression Equations of Shear Wave Velocities. Soils and Foundations, 32(1), 205-214. doi:https://doi.org/10.3208/sandf1972.32.205

Lee, S. H. H. (1990). Regression models of shear wave velocities in Taipei basin. Journal of the Chinese Institute of Engineers, 13(5), 519-532. doi:10.1080/02533839.1990.9677284

Ng, C. W. W., \& Yung, S. Y. (2008). Determination of the anisotropic shear stiffness of an unsaturated decomposed soil. Géotechnique, 58(1), 23-35. doi:10.1680/geot.2008.58.1.23

Ohta, Y., \& Goto, N. (1978). Empirical shear wave velocity equations in terms of characteristic soil indexes. Earthquake engineering \& structural dynamics, 6(2), 167-187.

Park, C., Miller, R., Rydén, N., Xia, J., \& Ivanov, J. (2005). Combined use of active and passive surface waves. Journal of Environmental and Engineering Geophysics, 10(3), 323-334.

Park, C. B., Miller, R. D., \& Xia, J. (1999). Multichannel analysis of surface waves. Geophysics, 64(3), 800-808.

Pennington, D. S., Nash, D. F., \& Lings, M. L. (2001). Horizontally mounted bender elements for measuring anisotropic shear moduli in triaxial clay specimens. Geotechnical Testing Journal, 24(2), 133-144.

Pitilakis, K., Raptakis, D., Lontzetidis, K., TikaVassilikou, T., \& Jongmans, D. (1999). Geotechnical and geophysical description of EURO-SEISTEST, using field, laboratory tests and moderate strong motion recordings. Journal of Earthquake Engineering, 3(03), 381-409.

Seed, H. B., Idriss, I. M., \& Arango, I. (1983). Evaluation of Liquefaction Potential Using Field Performance Data. Journal of Geotechnical Engineering, 109(3), 458-482. doi:doi:10.1061/(ASCE)07339410(1983)109:3(458)

Shirley, D. J., \& Hampton, L. D. (1978). Shear-wave measurements in laboratory sediments. The Journal of the Acoustical Society of America, 63(2), 607-613.

Sykora, D. W. (1983). Correlations of in situ measurements in sands of shear wave velocity, soil characteristics, and site conditions. Available from http://worldcat.org /z-wcorg/ database.

Ulugergerli, E. U., \& Uyanik, O. (2007). Statistical correlations between seismic wave velocities and SPT blow counts and the relative density of soils. Journal of Testing and Evaluation, $35(2)$,

187-191.

ahmed.hasan@su.edu.krd, yousif.mawlood@su.edu.krd, azad@andrealab.com, hawkar.ibrahim@su.edu.krd 